This article may not exactly replicate the final version published in Neuroscience and Biobehavioral Reviews. It is not the copy of record. http://www.sciencedirect.com/science/article/pii/

$\underline{\text { S0149763416303177 }}$

\title{
Rethinking primate facial expression: A predictive framework
}

Bridget M. Waller, Jamie Whitehouse, Jérôme Micheletta

Centre for Comparative and Evolutionary Psychology, Department of Psychology, University of Portsmouth, UK

\begin{abstract}
Primate facial expression has long been studied within a framework of emotion that has heavily influenced both theoretical approaches and scientific methods. For example, our understanding of the adaptive function and cognition of facial expression is tied to the assumption that facial expression is accompanied by an emotional internal state, which is decipherable by others. Here, we challenge this view and instead support the alternative that facial expression should also be conceptualised as an indicator of future behaviour as opposed to current emotional state alone (Behavioural Ecology View, Fridlund, 1994). We also advocate the use of standardised, objective methodology (Facial Action Coding System, FACS) to avoid making assumptions about the underlying emotional state of animals producing facial expressions. We argue that broadening our approach to facial expression in this way will open new avenues to explore the underlying neurobiology, cognition and evolution of facial communication in both human and non-human primates.
\end{abstract}

\section{Introduction}

Scientific progress is achieved through building on frameworks that others have established. Such cumulative processes are key to human productivity. However, dominant ideas can become entrenched and inhibit the field from moving in alternative, or even complementary, directions. Primate (including human) facial expression has long been studied as synonymous with emotion; which, we argue, can inhibit scientists from exploring the phenomenon of facial expression fully. Several landmark findings (e.g. referential vocalisations: Seyfarth et al., 1980) would not have been achieved if the notion of a strict separation between human language and animal communication was not challenged, and replaced with a continuum. Likewise, we argue it is crucial to consider (and challenge) the bedrock on which the study of primate facial expressions is currently standing.

\section{The emotional framework and its limitations}

The classification of animal signals as emotional or cognitive has existed for a long time, particularly as scientists have tried to identify aspects of animal communication that might rely on cognition in a similar way to human language. However, the tendency to analyse animal signals as either one or the other, although common, has been questioned as overly simplistic by several scientists (Watson et al., 2015; Wheeler and Fischer, 2012). Despite calls for an alternative Behavioural Ecology View (Fridlund, 1994), where facial expressions are considered in terms of their likely function in social interaction, a strong link between emotion and animal facial expression has been made since Darwin's (1872) seminal work "The Expressions of the Emotions in Man and Animals". Darwin's observations of similarity between the 
behaviour that humans and non-human animals produce in similar social contexts, lead him to conclude that psychology as well as morphology is continuous between species. Darwin was also heavily influenced by Duchenne's experimental induction of facial movements in humans (Duchenne, 1862), and, like Duchenne, considered facial expressions to be readouts of internal emotional state. Importantly, Darwin did not consider facial expressions to necessarily be functional adaptations, a fact often missed by modern researchers (Barrett, 2011; Fridlund, 1994). Instead, Darwin thought that expressions are instinctual reflexes (or learned associations) of emotion that are often vestigial from an evolutionary perspective. Darwin did consider the communicative aspect of facial expressions, but only in the sense that the felt emotion can be understood by observers, and not why this might be functional. There is a large body of work confirming that facial expressions are indeed associated with felt emotion (Levenson et al., 1990), yet this focus on the proximate mechanisms of facial expressions is highly pervasive and now dominates over consideration of ultimate function. There are functionalist accounts of facial expressions, but some focus on the benefits to the individual when experiencing the emotion, such as the physiological regulatory function of facial expressions. For example, Susskind et al. (2008) suggested that human fear expressions function to prepare individuals to cope with threat. They demonstrated that the typical expression of fear allowed participants to have a larger visual field and faster eye movement, as well as an increase in nasal volume and air velocity during inspiration. The authors explained that these adjustments could facilitate the detection and escape from a threat. In contrast, the disgust face led to the opposite pattern, minimising sensory input (Susskind et al., 2008), which they argue functions to block aversive stimuli. Shariff and Tracy (2011) proposed that where a social communication function of facial expression does exist, this is likely to be a secondary function exapted from physiologically adapted origins. Shariff and Tracey's two stage model of the evolution of emotional expressions puts the expresser of emotion as the central figure, and the observer of the expression as benefitting later and indirectly. The authors argue that facial expressions initially evolved as components of the emotional response that function to prepare the body to respond. Socially complex animals then gained additional fitness benefits from communicating important social information. For example, pride and shame are thought to help individuals navigate social hierarchies (Shariff and Tracy, 2011).

This model for facial expression evolution is a worthy attempt at reconciling emotional and communicative views of expression. However, while it is attractive for humans it does not work as well when taking a comparative approach. Fear, for example, can be used to illustrate this point. Fear as a feeling state is unlikely to be unique to humans as 1) physiological correlates of fear can be seen in many other animals (Panksepp, 1990) and 2) it makes adaptive sense for animals to experience a feeling state that helps them avoid threats. However, the facial expression associated with fear in humans is not shared with other animals. Many other facial expressions do have clear counterparts in other animals, such as the expressions of smiling and laughing (Van Hoof and Hinde, 1972), food aversion (Steiner et al., 2001) and possibly anger (Parr et al., 2010) but not fear. If the function of the human facial expression of fear is to widen the eyes and prepare the individual to cope with threat, this could also be adaptive for other animals, particularly those whose faces are encumbered more so than the relatively hairless and browless human face. If so, why is this same facial expression not seen in other animals? It could be because the primary function of the fear facial expression in humans is not the physiological regulatory function, but instead the signal function afforded by the increased exposure of the sclera. Sclera is a characteristic feature of human eyes and is much less salient in other animals (including other primates: Kobayashi and 
Kohshima, 2001), and the detection of sclera is key to the perception of fear facial expressions in humans (Whalen et al., 2004). One reason that other animals might not have evolved fear expressions, is that it could be maladaptive to expose vulnerable internal states such as fear to others. Many animal societies are based on systems of competition rather than cooperation (Clutton-Brock, 2016), and it might only be in the context of cooperation that fear signals evolve. Thus, fear expressions (as well as other signs of weakness such as pain, or frustration: Waller et al., 2014) could be absent in many species which are not based on cooperation. Humans are unusual in the high level of cooperation they exhibit between both related and unrelated individuals (Tomasello, 2008). Thus, fear facial expressions may have evolved in humans due to the adaptive value in communicating fear to others in order to receive support, and not primarily as physiological regulators. In which case, Shariff and Tracey's (2011) two stage model for the evolution of facial expressions is less convincing. Of course, it could also be adaptive to express fear in competitive situations, for example to reduce the risk of aggression. In this case, however, if there is a fear expression in nonhuman primates, it is not anatomically homologous to the human facial expression of fear.

A primary focus on the proximate (emotional) mechanisms of facial expression is limiting for additional reasons, particularly when conducting comparative research. First, and most simply, we cannot be sure if another individual's experience of emotion is the same as one's own, and so in some circumstances scientists might attribute emotion incorrectly. This is particularly risky in comparative research, where non-human emotion could be very different to human emotion, but could also be the case when dealing with nonlinguistic humans such as infants. Thus, even if the felt emotion does have important self-regulatory function in non-human animals, there could still be a fair amount of guesswork before working out what that might be. Second, the emotion thought to underlie an expression is often used as part of the description of that expression. For example, primate facial expressions are often described using subjective emotional terms, such as fear grimace. These emotional descriptions may or may not be correct, but regardless can affect our perception of the appearance and morphology of facial expressions (Waller et al., 2007), potentially rendering our descriptions inaccurate. Third, without objective descriptions focussing on the morphology of an expression, rather than the emotional content, whether scientists are referring to the same phenomena when discussing these expressions is unclear. If the goal is to make unbiased scientific descriptions of facial expressions, clarity and objectivity are crucial. Finally, and most importantly, the premise that facial expressions are emotional sets them apart from other modalities of primate communication, such as gestures and vocalisations (Liebal et al., 2013; Slocombe et al., 2010). For example, in comparison to vocalisations, more attention is paid to the producer of facial expression rather than the receiver, and studies are less likely to be experimental and aim to quantify the social consequences of the signals (Liebal et al., 2013; Slocombe et al., 2010). Scientists might be focussing more on the expresser of the facial expressions actions precisely because they are assuming that the function is physiological and regulatory rather than communicative. Any additional (or even primary) function evidenced by quantifying the response in a receiver (Guilford and Dawkins, 1991) could be overlooked within such a framework. However, it is also possible that (as with gestures) the role of the receiver in facial expression is simply difficult to test (but see Micheletta et al., 2015; Parr et al., 1998; Waller et al., 2016) in contrast to vocalisations (Fischer et al., 2013). In sum, for each primate communicative modality we have more or less data on different aspects of the phenomena, rendering comparisons between modalities problematic. Our broad generalised conclusions about what is and is not characteristic of primate facial expression is not based on a complete dataset. In short, primate facial expressions are 
studied more in terms of their proximate, mechanistic properties and less in terms of their ultimate, evolutionary and communicative function (sensu Tinbergen, 1963). Of course, all levels of Tinbergen's famous four questions deserve attention and any strong focus on one at the expense of the others leaves an incomplete picture.

\section{Moving beyond emotion-objectivity}

We argue that in order to build a more complete picture of primate facial expression we need to decouple it from a framework where it is considered synonymous with emotion (as suggested by Fridlund, 1994). Yet, the study of facial expression has become so intertwined with the study of emotion that it can be hard to conceive of a way forward for research without combining the two. We suggest that there are two particularly important steps we need to take to release facial expression from emotion.

First, it is important to avoid vague emotional terms for facial expressions, as we might overlook important characteristics about the exact form of the expression. For example, primate facial expressions are rarely static and invariant and are thus not always suited to lumping into broad categories. Facial expressions can be composed of multiple components which occur dynamically (different onsets, offsets, durations) over a period of time. For example, the crested macaque (Macaca nigra) lipsmack display has been described as a composite and multimodal signal in published repertoires (Thierry et al., 2000) but until recently, the role of these different components had not been analysed. Micheletta et al. (2013) investigated whether the specific composition of the lipsmack affected the social outcomes of interactions when lipsmacks were produced. Lipsmacks composed of both vocal (soft grunt) and visual (lip movement, scalp retraction, teeth exposure and/or head turn) components were more likely to result in affiliative interactions, demonstrating a level of complexity in the production and role of the lipsmack than previously understood. Emotional labels are not necessary to describe this expression and it is not clear how this would be helpful when considering the form and function of this particular facial expression.

Instead, an objective system for the quantification of animal facial expressions is necessary and can be found in the Facial Action Coding System (FACS: Ekman et al., 2002). Initially developed for humans, FACS has been modified for use with various primate species: chimpanzees (ChimpFACS: Vick et al., 2007), macaques (Julle-Danière et al., 2015; Parr et al., 2011), gibbons (Waller et al., 2012) and orangutans (Caeiro et al., 2012). FACS is a standardised, objective method for recording facial movements based on the underlying anatomy (see Fig. 1), and reduces facial expressions to component movements, including dynamic and extremely subtle aspects if needed. Importantly, there is no need to use emotional terms when describing facial expressions using FACS, which allows scientists to explore facial expressions in novel ways. Using this objective methodology, we demonstrated that orangutan facial expressions can meet some of the criteria for intentional production (Waller et al., 2015), a cognitive characteristic often attributed only to primate gesture (eg. Liebal et al., 2013; Pika, 2008) and only recently to primate vocalisations (Schel et al., 2013). Using FACS to record the components of the open mouth faces used during play interactions (e.g whether the jaw was dropped slightly [AU26] or stretched open [AU27], whether the upper lip was retracted [AU10] and whether the lip corners were retracted [AU12]), we demonstrated that the facial expressions were more intense and more complex when the expresser was facing the play partner. Sensitivity to the attentional stance of another is a commonly used criterion for intentional production of primate communication. As primate behaviours are often categorised as 
underpinned by either intentional or emotional production (Tomasello, 2008), we argued that an emotional approach to facial expression was inhibiting scientists from testing for intentionality in facial expression production. Crucially, using objective methods such as FACS makes it easier to conduct quantitative studies such as this.

\section{Moving beyond emotion-a predictive framework}

The second step we need to take to release facial expression from emotion, is to think more clearly about what facial expressions are actually for. Classically, facial expressions are seen as the expression of emotion experienced by the producer of the expression. This may be one characteristic of facial expressions, but this definition alone is not sufficient to help researchers understand both the evolution and function of facial expressions because it does not address the effect facial expression have on receivers. Here, we advocate an alternative view proposed by Alan Fridlund in 1994, the Behavioural Ecology View. Within this perspective, facial expressions are not just as indicators of current emotional state, but are also indicators of future behaviour.

There is evidence that facial expressions can affect the decisions made by the individuals' who witness them. As early as 1971, Miller (1971) demonstrated this phenomenon using a novel experimental design. A macaque was shown a warning sign prior to being exposed to an electric shock. The macaque reacted by displaying a silent-bared teeth facial expression. An observer macaque was able to use this signal to press a lever and therefore avoid exposure to the upcoming electric shock themselves. Thus, the facial expression acted as an indication of forthcoming events (allowing the witness to anticipate what might happen next). More recently, Buttelmann et al. (2009) tested the ability of chimpanzees, bonobos, gorillas and orangutans to understand others' facial expressions. When presented with food hidden under two containers, great apes were able to select the food baited container based on the target and valence of the human experimenter's facial expressions (Buttelmann et al., 2009). In the final experiment, the apes' understand that the experimenter had subsequently eaten the food they had reacted positively towards, and so choose the alternative box (which is still baited with food). Thus, the subjects' could predict the experimenter's behaviour based on his facial expression. In a similar type of experiment, capuchin monkeys (Cebus apella) modified their behaviour in response to the facial expressions of a conspecific (Morimoto and Fujita, 2011, 2012). A demonstrator capuchin was presented with boxes containing stimuli which reliably elicited either a positive, a neutral or a negative response. An observing capuchin witnessed the reaction of the demonstrator, who was then given access to the same box (see Fig. 2). The observer modified their response to the boxes based on the facial expressions of the demonstrator. Specifically, the capuchins reached for the box for longer when the conspecific demonstrator displayed eyebrow flashes, an affiliative facial expression often followed by physical contact. Therefore, the capuchin used the facial expressions of a conspecific to predict whether the box contained favourable stimuli.

The novel and important conclusion from these experiments is that facial expressions can provide useful information about hidden or unseen objects in the environment. Thus, these experiments show that facial expressions can be useful to social observers. However, facial expressions are usually directed at conspecifics in the context of social interactions, and not towards inanimate objects. 


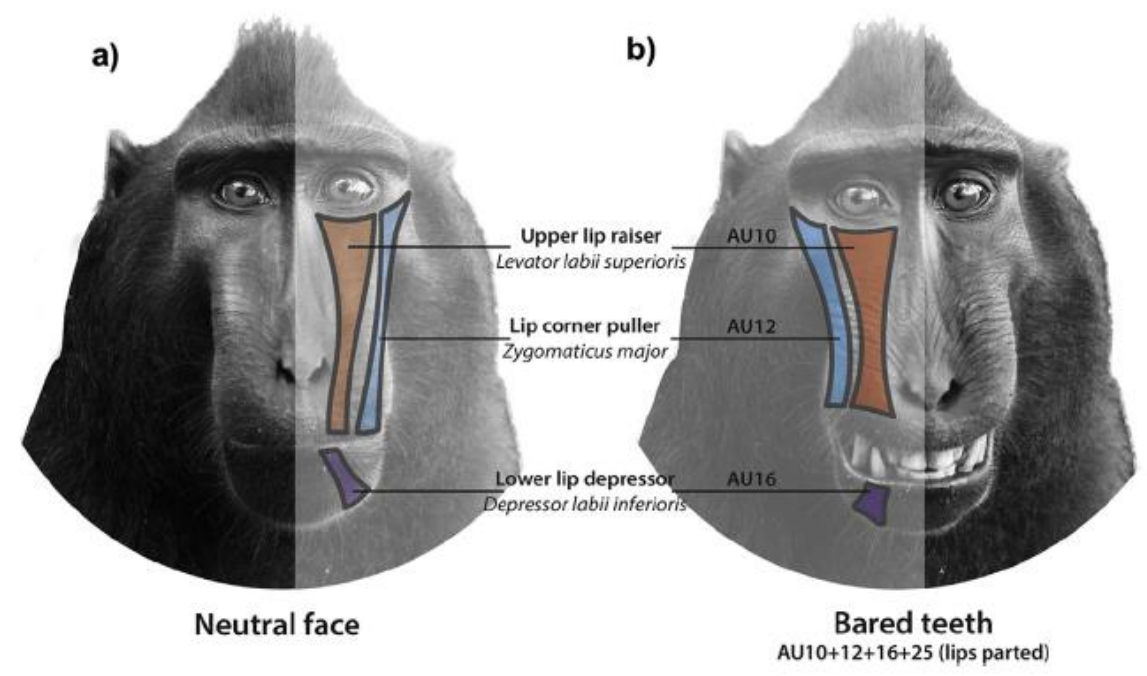

Fig. 1. A facial expression coded using the Facial Action Coding System (FACS). a) Neutral face with facial muscles indicated. b) Facial muscles contracted and therefore presence of Action Units (AUs) coded. FACS modified for use with different species are based on the human FACS (Ekman et al., 2002).
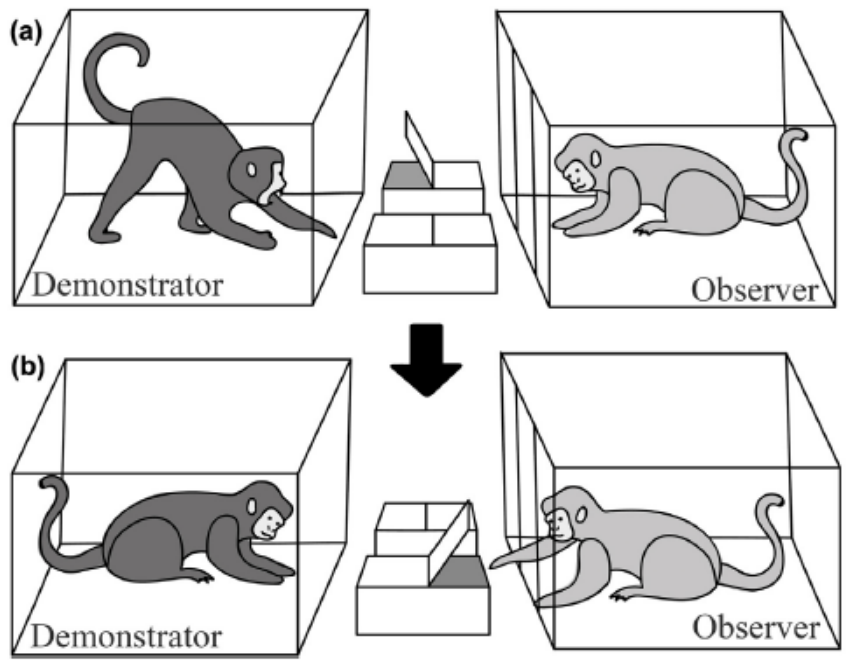

Fig. 2. Expressions modify future behaviour. Adapted from Morimoto and Fujita (2012). a) A demonstrator monkey directed expressions towards one of two boxes, which contained either a positive (apple) or negative (dog puppet) item. The observer monkey could not see the contents, but could see the expressions of the demonstrator. Only one box was open. b) After the object was shown to the demonstrator, the observer could then choose one of the boxes. When the demonstrator displayed an expression with a positive valence, the observer was more likely to choose the open box. In contrast, after an expression with a negative valence, the observer was more likely to avoid the open box.

In which case, the ability to choose objects based on observed facial expression should be generalizable to social circumstances. Facial expressions should also function as indicators of likely outcomes during social interactions. In a sense, this perspective is building on a classic approach to communicative events as ritualised behavioural intention movements (e.g. Hinde, 1966), which although highly established throughout behavioural biology, may have been overshadowed by the ubiquitous emotional framework. Using a variant of the match-to-sample task, we tested crested macaques' ability to associate video sequences of social interactions to their most likely outcome (Waller et al., 2016). We first trained the 
macaques to match video sequences of behaviour with a corresponding outcome (e.g. sexual presentation with eventual mating), using various controls and alternative outcomes. One macaque successfully passed this training stage during which only the correct choices were reinforced. We then tested the macaque with novel video sequences showing one individual approaching another individual. We manipulated the last frame to show either a neutral face, a silent bared-teeth face, an open-mouth threat or an openmouth bared teeth scream face, and then presented the macaque with different social outcomes to choose between. The macaque chose different outcomes depending on the facial expression (see Fig. 3). The macaque chose a peaceful outcome more often after seeing the approaching macaque with a bared-teeth (more than any other expression). In contrast, the macaque chose a conflict outcome (injury) most often after the approach ended with a neutral expression. This last result most likely reflects the potential for conflict when no information is provided by the approaching individual. Interestingly, all facial expressions seemed to indicate reduced likelihood for conflict. Although this might initially seem counter-intuitive, the function of communicative signals in the agonistic context is to resolve the conflict without having to escalate to physical aggression (Clutton-brock and Albon, 1979; Preuschoft and van Schaik, 2000), and so this outcome still fits with the overall proposal. Although fundamentally a proof of concept, this kind of study should facilitate future investigation of the processing of facial expression by receivers.

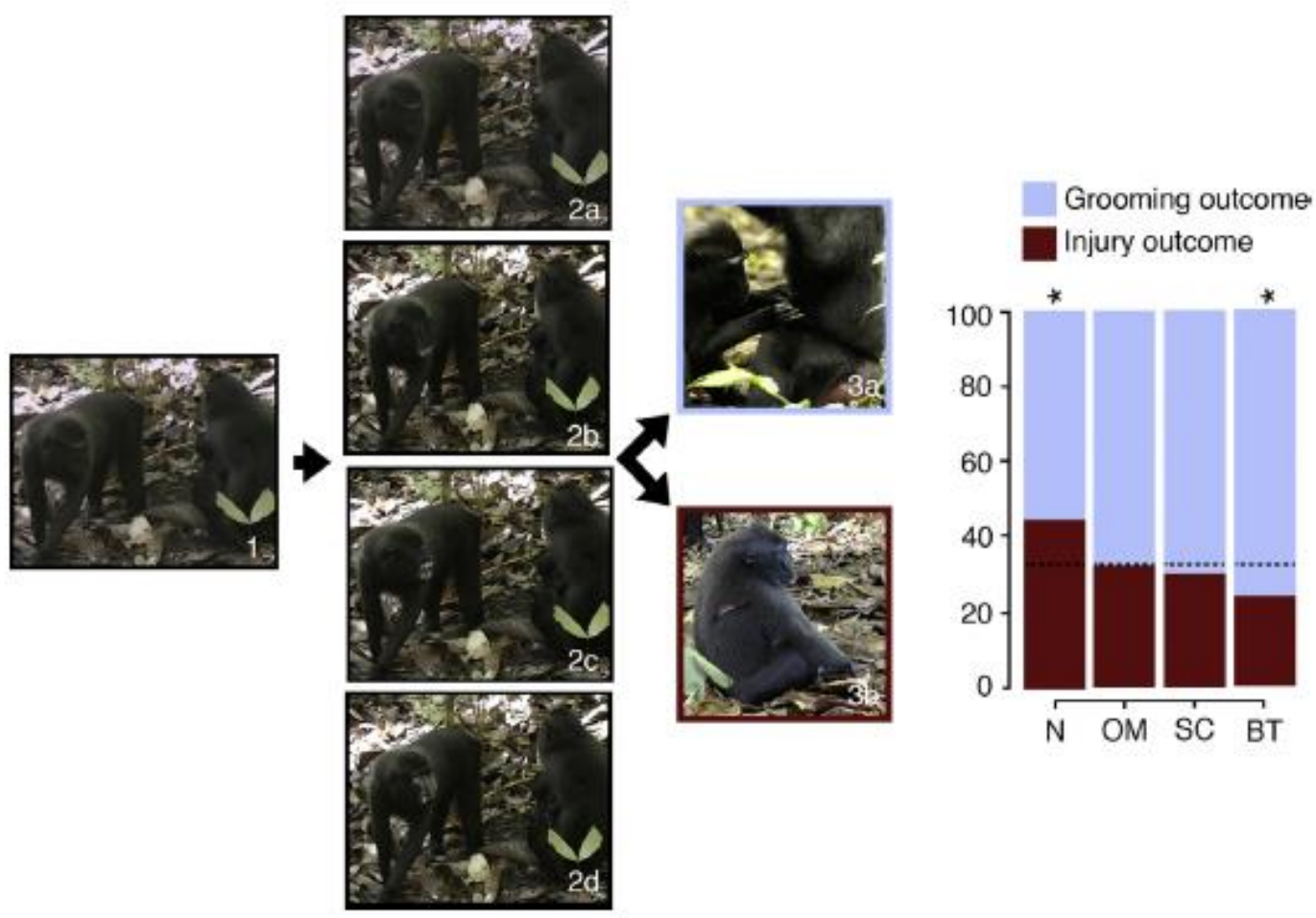

Fig. 3. Predictive value of facial expression in social interaction. Taken from Waller et al. (2016). A subject was presented with a video sequence of one unknown individual approaching another on a touchscreen (1). The final frame of this video remained on the touchscreen, and one individual in the image was manipulated to either display: (2a) a neutral face (N), (2b) an open-mouth threat (OM), (2c) a scream face (SC), or (2d) a bared-teeth face (BT). Once the subject touched this image, a choice of social outcomes was then presented. This was either a (3a) grooming, or (3b) injury outcome. The percentage of choice for each facial expression is shown on the right panel. The dotted line represents the expected values derived from the Chi-squared analysis. The presence of all facial expressions reduced the likelihood of the subject predicting a conflict outcome. This figure is distributed under the terms of the Creative Commons Attribution 4.0 International License (http://creativecommons.org/licenses/by/4.0/). 


\section{Predictive framework: cognition}

We argue that increasing focus on the predictive value of facial expression will open new avenues to explore the underlying cognition, neurobiology, and evolution of facial expression in both human and nonhuman primates. If facial expressions can be used by the receivers to adjust their behaviour based on the likely future behaviour of the sender, this raises new questions about how facial expressions are perceived and processed by the receiver. We know that several species of primate can accurately categorise facial expressions based on appearance (e.g. Parr and Heintz, 2009), emotional valence (Parr, 2001), the presence of salient features (Parr et al., 2008) or their functional similarities (Micheletta et al., 2015). However, if processing facial expressions involves a predictive aspect, this may involve an additional layer of possibly more complex cognitive mechanisms, and facial expression may start to be seen as a more central factor in social cognition.

If facial expression observers can extract more from facial expressions than their temporary and fixed emotional content, this might also contradict some current views of facial expression and how they are 'understood' by recievers, which is often seen as a largely automatic and reflexive process. For example, the most basic mechanism proposed to be involved in processing facial expressions is spontaneous, reflexive emotional contagion (Hatfield et al., 1994), in which emotion is a central concept. In this process, the receiver automatically experiences the same psychological state as the sender. This emotional contagion has been linked to rapid facial mimicry, the rapid $(<1 \mathrm{~s})$ production of the same facial expression by the receiver (Dimberg et al., 2000). Rapid facial mimicry has been documented in chimpanzees (Davila-Ross et al., 2011), orangutans (Davila Ross et al., 2008) and geladas (Mancini et al., 2013a) in the context of play. In both chimpanzees and geladas (Davila-Ross et al., 2011; Mancini et al., 2013b), play bouts including rapid mimicry of play faces were longer, possibly because it reduces the uncertainty regarding the ongoing interaction. In this context, rapid facial mimicry seems to facilitate the exchange of information and therefore the coordination of playful interactions, which is thought to allow primates to improve their social skills as well as functioning to establish and maintain social bonds. In negatively valenced contexts such as aggression, reflexive emotional contagion could also be advantageous if it triggers physiological regulation processes (e.g. fear expressions facilitating escape from threat: Susskind et al., 2008). However studies documenting the occurrence of emotional contagion in primates appear to be restricted to the context of play. Of course, this does not mean that contagion does not occur in other contexts or in response to other facial expressions, but rather that researchers have not yet extended their investigation to other contexts and expressions. However, in one study, Mancini et al. (2013a) have documented the lack of rapid facial mimicry in response to geladas' lip-smacks, another facial expression emitted in positive social interactions.

Despite being widely studied, the contagion model is questionable (Dezecache et al., 2015). From a functional perspective, it is unlikely that the default response to another's facial expression should always be the same as the sender's. In fact, responses to facial expressions often vary in light of several social and contextual factors and are rarely identical to the sender's (with the exception of play). For example, threats might not be responded to in the same way when they are observed in dominant individuals and subordinates, or when performed by inand out-group members (Hess et al., 2009). In fact, in many species, facial threats are often responded to with formal signals of subordination and/or avoidance rather than 
facial threats (e.g. De Waal and Luttrell, 1985). Primates are also very good at following the gaze of conspecifics (Tomasello et al., 1998), which means that they can adopt different responses to facial expressions depending on who (or what) is the target of the facial expression. Of course, by-standers do not necessarily react in the same way as the actual target of the facial expression, which makes sense from a functional perspective.

There are also a number of instances where the behaviour of the receiver differs in response to the same expression depending on social context. In several species of macaques, the well-known silent-bared teeth expression can be produced in response to very different stimuli. It can be produced in aggressive contexts where it generally triggers the end of the conflict, or in peaceful contexts where it can lead to grooming or mating (Duboscq et al., 2013; Thierry et al., 1989). If individuals understand the facial expressions of others by experiencing the same emotion, how does this facilitate such complex and flexible responses? The contagion model is simply not sufficient to explain how facial expressions are detected and processed when facial expressions are embedded in complex social interactions with various possible social outcomes. In sum, the contagion model may provide a possible mechanism by which receivers can acquire information regarding the psychological state of senders, but it does not explain if/how receivers integrate context and can then act on this information, particularly if they need to respond flexibly. In contrast, in a predictive framework such as the Behavioural Ecology View (Fridlund, 1994), the facial expressions of others are seen as indications of their likely future behaviour, observers are not limited to responding in the same way as the sender (either by experiencing the same emotion, or experiencing physiological regulation). Instead, they can respond depending on what is most beneficial to them as an individual, in light of the useful information that someone else is likely to act in a certain way. However, if this predictive framework is correct, it suggests that an extra (or simply different) layer of cognition could be at work, which forces us to rethink how facial expressions are processed.

In order to free facial expression from an emotional framework, we need to embed it in the social interaction from the start. Currently, facial expressions are somewhat isolated from the contexts and dynamics in which they occur. This is not the case with all facial movements, which we argue has a profound effect on how the phenomenon is studied. Gaze direction, for example, is an aspect of facial expression (in the sense that it is a facial feature defined by its relation to other facial features) that is not considered to be intrinsically emotional. Instead, gaze direction is considered to provide information: when gaze is directed towards something (or someone), it can provide information to others about the object of the sender's attention (if observers have the ability to follow the actor's gaze). As such, responses to gaze cues are often connected to the suite of skills considered to be building blocks toward theory of mind and empathy e.g. gaze following tasks are included in the widely used battery of tasks to test the extent of theory of mind in primates: (Herrmann et al., 2007). Crucially, gaze cues mean less when isolated from the social interaction; it is only when the object of gaze is included in the phenomenon that they become meaningful and we truly understand the cognition associated with interpreting them. Likewise, with facial expression, perhaps it is only through embedding facial expression back in the social interaction that we can truly understand the underlying cognition.

If facial expressions can be used to predict the likely behaviour of others, and adjust their behaviour accordingly, what cognition might underlie this? Responses could still be reflexive, although the likelihood of this is reduced when we consider the vast number of factors that could contribute to a vast range of 
possible outcomes. A mandatory response to facial expressions might not make as much sense as a more cognitive, flexible response. There is ample evidence documenting primates' ability to adjust their behaviour depending on the behaviour of others (reviewed in Rosati and Hare, 2012), and several mechanisms have been put forward to explain their ability to do so. It is possible that individuals develop a set of behavioural rules after repeatedly facing the same or similar situation during their existence. At the other extreme, it is also possible that individuals attribute mental states to others and are capable of reasoning about those mental states to achieve the best outcome using a full-blown, human-like theory of mind. Although currently there are very few intermediate mechanisms, a few alternatives have been proposed recently (Butterfill and Apperly, 2013; Whiten, 2013). There is a lively ongoing debate regarding these cognitive abilities (Heyes, 2015), and our goal here is not to contribute to this debate by favouring one alternative over the other, but to encourage others to envisage what the mediating role of facial expressions in this process could be and what it could entail.

\section{Predictive framework: neurobiology}

Our understanding of the neurobiology underlying facial expression production and perception is extensive. However, revisiting the framework with which we study facial expressions could open new avenues. We know that the neural network for facial expression systems spans over half of the neocortex and includes many bilateral regions of the primate brain, and that the core systems are situated in the occipitotemporal regions of the visual cortex in humans (Haxby et al., 2000). The key structures involved include those in the temporal lobe, such as superior temporal sulcus and the interior temporal cortex, as well as the amygdala and the premotor cortex (Gothard et al., 2007; Haxby et al., 2002; Liebal et al., 2013). There is increasing evidence for similar neural processes in non-human primates (Parr and Hecht, 2011), suggesting a functional homology of face and expression perception throughout the primates (Liebal et al., 2013). However, our understanding and interpretation of these neural systems, and the function of the neural structures involved during the perception of facial expressions are derived through our current knowledge of what facial expressions are and what they do. By constraining our understanding of facial expressions within an emotional framework, we may be subsequently constraining our understanding of the neurobiological systems we use to process them.

If facial expressions are not only communicating the emotional state of an individual but instead, information about the intentions and future behaviour of the actor, this may lead to a different interpretation of the systems which we currently attribute to the production and perception of emotion. The study of the neural mechanisms for emotional perception for example, is often approached through the presentation of emotionally salient stimuli, of which images and videos of facial expressions are often included (Breiter et al., 1996; Morris et al., 1996; Phillips et al., 2003). Different neuronal responses in the amygdala during the perception of different facial expressions have been recorded, with happy and fearful faces eliciting quantifiably different neural patterns when observed by humans (Morris et al., 1996). But, because of the assumption that these expressions are a product of their corresponding affective state, these neural changes tend to be directly linked to the perception of emotion; where the intensity of neural response is attributed to the intensity of the emotion felt by the displaying individual. Instead, it could be these neural changes are not related to the salience of faces, but the urgency in which an individual needs to assess another's intentions and prepare an appropriate response. The adaptive value of responding to 
fearful or aggressive expressions is likely to be greater than that of responding to happy faces, and it would be sensible that the neural responses would reflect this. Indeed, the role of the amygdala in interpreting facial expressions has long been explored, and is currently seen less as detecting emotion, and more as interpreting ambiguous social information in context (Hoffman et al., 2007). When examining the neural areas associated with facial expression, we may be uncovering importantneural mechanisms whichcontribute to other mental abilities such as affective forecasting and behaviour reading (Krebs and Dawkins, 1978; Wilson and Gilbert, 2005). So, for us to be able to comprehend and interpret the relationship between the neural processes and function of facial expression, it is imperative that we first take a step back and attempt to fully understand why these behaviours exist to begin with.

\section{Predictive framework: evolution}

The ability to attend and respond to the emotions of others, although an arguably adaptive strategy in the maintenance of complex social systems (Clay and de Waal, 2013), may not represent the most parsimonious explanation for the evolution of facial expression in animals. Instead, the ability to avoid harmful situations by predicting the likely behaviour of others could impose an enormous selection pressure on the evolution of behaviour throughout the animal kingdom. For example, signals that allow individuals to avoid interspecific and intraspecific conflict are extremely useful adaptations (eg. Alarm calling, Seyfarth et al., 1980; Reconciliation, De Waal and van Roosmalen, 1979). If facial expression themselves also reduce the likelihood of future conflict by allowing an individual to predict the future behaviour of others which experimental data is beginning to suggest (Buttelmann et al., 2009; Morimoto and Fujita, 2011, 2012; Waller et al., 2016), this could be a much simpler explanation for their selection then the perception and processing of complex emotions alone.

Attempts to promote an adaptationist approach to the evolution of human facial expression is not new, and have been made eloquently by several scholars (e.g. Fridlund, 1994; Schmidt and Cohn, 2001), Attempts have also been made to reconcile approaches between the human and non-human animal literature (e.g. Fridlund, 1994; Waller and Micheletta, 2013). But still, a tendency to focus on emotion reading as an explanation for the evolution of facial expression remains a dominant comparative approach (De Waal, 2011; Shariff and Tracy, 2011). It could be, of course, that information regarding both the individual's emotional state and their future intentions have influenced the evolution of facial expression, and so it may be just as problematic to ignore emotion altogether. By bridging the gap between these two schools of thought, of both the functional and causal aspects of facial expression, we could develop an improved framework to fully understand these behaviours (Tinbergen, 1963). In many ways the goal of Shariff and Tracy (2011) is also to integrate the functional and causal aspects of facial expression, which should be commended.

\section{Conclusion}

In sum, the vast majority of non-human primates exhibit facial movements as part of their behavioural repertoire. In accordance with scientific tradition, these are often labelled facial expressions and are thought to reflect the emotional state of the sender. The term facial expression invokes an emotional approach as there is an intrinsic assumption that something internal to the actor is being expressed. 
However, we argue that this emotional framework is limiting the field from moving forward to gain a deeper understanding of the form and function of facial expression within social interaction. We argue that a focus on the emotion centres scientific attention on the actor of the behaviour (rather than the wider social interaction), on proximate mechanisms, and crucially, on the present. We advocate an alternative, a predictive framework where facial expressions can be conceptualised as indicators of the actor's likely future behaviour (Fridlund, 1994). In line with a more classical ethological perspective, this framework sees facial expressions more as ritualised intention movements that can be used by others to gain useful information about potential future events and to reduce uncertainty. Rethinking facial expressions in this way allows us to embed the signals back into the social interaction and consider them in relation to other individuals, other behaviours, and of course other communicative events. Such an integrative approach has been integral in advancing our understanding of many aspects of biology, particularly communicative systems (e.g. communication; Partan and Marler, 1999; sensory perception; Ghazanfar and Schroeder, 2006). We propose that the production and perception of facial expression not only exist as part of a coordinated exchange of information, but also as part of an embodied multimodal system, where many aspects of communication, emotional experience, and cognition are working together during social interaction.

\section{Acknowledgements}

This work was funded by a Leakey Foundation Research Grant to Bridget Waller and Jerome Micheletta. We thank Hélène Meunier for inviting our participation in the "Cognition in Primates" Neurex Meeting 2015 and for inclusion in this special issue. We also thank Alan Fridlund for helpful comments on an earlier version of this paper.

\section{References}

Barrett, L.F., 2011. Was darwin wrong about emotional expressions? Curr. Dir. Psychol. Sci. 20, 400-406, http://dx.doi.org/10.1177/0963721411429125.

Breiter, H.C., Etcoff, N.L., Whalen, P.J., Kennedy, W.A., Rauch, S.L., Buckner, R.L., Strauss, M.M., Hyman, S.E., Rosen, B.R., 1996. Response and habituation of the human amygdala during visual processing of facial expression. Neuron 17, 875-887, http://dx.doi.org/10.1016/S0896-6273(00)80219-6.

Buttelmann, D., Call, J., Tomasello, M., 2009. Do great apes use emotional expressions to infer desires? Dev. Sci. 12, 688-698, http://dx.doi.org/10.1111/j. 1467-7687.2008.00802.x.

Butterfill, S.A., Apperly, I.A., 2013. How to construct a minimal theory of mind. Mind Lang. 28, 606-637, http://dx.doi.org/10.1111/mila.12036.

Caeiro, C.C., Waller, B.M., Zimmermann, E., Burrows, A.M., Davila-Ross, M., 2012. OrangFACS: a musclebased facial movement coding system for orangutans (Pongo spp.). Int. J. Primatol. 34, 115-129, http://dx.doi.org/10.1007/s10764012-9652-x.

Clay, Z., de Waal, F.B.M., 2013. Development of socio-emotional competence in bonobos. Proc. Natl. Acad. Sci. U. S. A. 110, 18121-18126, http://dx.doi.org/10. 1073/pnas.1316449110.

Clutton-Brock, T., 2016. Mammal Societies. John Wiley \& Sons. 
Clutton-brock, T.H., Albon, S.D., 1979. The roaring of red deer and the evolution of honest advertisement. Behaviour 69, 145-170.

Darwin, C., 1872. The Expression of the Emotions in Man and Animals, 1st ed. John Murray, London, UK.

Davila Ross, M., Menzler, S., Zimmermann, E., 2008. Rapid facial mimicry in orangutan play. Biol. Lett. 4, 27-30, http://dx.doi.org/10.1098/rsbl.2007.0535.

Davila-Ross, M., Allcock, B., Thomas, C., Bard, K.A., 2011. Aping expressions?

Chimpanzees produce distinct laugh types when responding to laughter of others. Emotion 11, 1013-1020, http://dx.doi.org/10.1037/a0022594.

De Waal, F.B.M., Luttrell, L.M., 1985. The formal hierarchy of rhesus macaques: an investigation of the bared-teeth display. Am. J. Primatol. 9, 73-85.

De Waal, F., van Roosmalen, A., 1979. Reconciliation and consolation among chimpanzees. Behav. Ecol. Sociobiol. 5, 55-66.

De Waal, F.B.M., 2011. What is an animal emotion? Ann. N. Y. Acad. Sci. 1224, 191-206, http://dx.doi.org/10.1111/j.1749-6632.2010.05912.x.

Dezecache, G., Jacob, P., Grèzes, J., 2015. Emotional contagion: its scope and limits. Trends Cogn. Sci. 19, 297-299, http://dx.doi.org/10.1016/j.tics.2015.03.011.

Dimberg, U., Thunberg, M., Elmehed, K., 2000. Unconscious facial reactions to emotional facial expressions. Psychol. Sci. 11, 86-89, http://dx.doi.org/10. 1111/1467-9280.00221.

Duboscq, J., Micheletta, J., Agil, M., Hodges, K., Thierry, B., Engelhardt, A., 2013. Social tolerance in wild female crested macaques (Macaca nigra) in Tangkoko-Batuangus Nature Reserve, Sulawesi, Indonesia. Am. J. Primatol. 75, 361-375, http://dx.doi.org/10.1002/ajp.22114.

Duchenne, G.B., 1862. Mécanisme de la Physionomie Humaine, 1st ed. Jules Renouard, Paris.

Ekman, P., Friesen, W.V., Hager, J.C., 2002. The Facial Action Coding System (FACS). Research Nexus, Salt Lake City.

Fridlund, A.J., 1994. Human Facial Expression: An Evolutionary View. Academic Press, San Diego, CA.

Fischer, J., Noser, R., Hammerschmidt, K., 2013. Bioacoustic field research: a primer to acoustic analyses and playback experiments with primates. Am. J. Primatol. 75 (7), 643-663, http://dx.doi.org/10.1002/ajp.22153.

Ghazanfar, A.A., Schroeder, C.E., 2006. Is neocortex essentially multisensory? Trends Cogn. Sci. 10, 278285, http://dx.doi.org/10.1016/j.tics.2006.04.008.

Gothard, K.M., Battaglia, F.P., Erickson, C.A., Spitler, K.M., Amaral, D.G., 2007. Neural responses to facial expression and face identity in the monkey amygdala. J. Neurophysiol. 97, 1671-1683, http://dx.doi.org/10.1152/jn.00714.2006.

Guilford, T., Dawkins, M.S., 1991. Receiver psychology and the evolution of animal signals. Anim. Behav. 42, 1-14, http://dx.doi.org/10.1016/S0003-3472(05)80600-1.

Hatfield, E., Cacioppo, J.T., Rapson, R.L., 1994. Emotional Contagion. Cambridge University Press, Paris.

Haxby, J.V., Hoffman, E.A., Gobbini, M.I., 2000. The distributed human neural system for face perception. Trends Cogn. Sci. 4, 223-233, http://dx.doi.org/10. 1016/S1364-6613(00)01482-0.

Haxby, J.V., Hoffman, E.A., Gobbini, M.I., 2002. Human neural systems for face recognition and social communication. Biol. Psychiatry 51, 59-67, http://dx. doi.org/10.1016/S0006-3223(01)01330-0. 
Herrmann, E., Call, J., Hernández-lloreda, M.V., Hare, B., Tomasello, M., 2007. Humans have evolved specialized skills of social cognition: the cultural intelligence hypothesis. Science 317 (80), 13601366, http://dx.doi.org/10. 1126/science.1146282.

Hess, U., Adams, R.B., Kleck, R.E., 2009. The face is not an empty canvas: how facial expressions interact with facial appearance. Philos. Trans. R. Soc. Lond. B. Biol. Sci. 364, 3497-3504, http://dx.doi.org/10.1098/rstb.2009.0165.

Heyes, C., 2015. Animal mindreading: what's the problem? Psychon. Bull. Rev. 22, 313-327, http://dx.doi.org/10.3758/s13423-014-0704-4.

Hinde, R.A., 1966. Ritualization and social communication in rhesus monkeys. Philos. Trans. R. Soc. Lond. B Biol. Sci. 251, 285-294, http://dx.doi.org/10.1098/ rstb.1966.0012.

Hoffman, K.L., Gothard, K.M., Schmid, M.C., Logothetis, N.K., 2007. Facial-expression and gaze-selective responses in the monkey amygdala. Curr. Biol. 17, 766-772, http://dx.doi.org/10.1016/j.cub.2007.03.040.

Julle-Danière, É., Micheletta, J., Whitehouse, J., Joly, M., Gass, C., Burrows, A.M., Waller, B.M., 2015. MaqFACS (Macaque Facial Action Coding System) can be used to document facial movements in Barbary macaques (Macaca sylvanus). PeerJ 3, e1248, http://dx.doi.org/10.7717/peerj.1248.

Kobayashi, H., Kohshima, S., 2001. Unique morphology of the human eye and its adaptive meaning: comparative studies on external morphology of the primate eye. J. Hum. Evol. 40, 419-435, http://dx.doi.org/10.1006/jhev.2001.0468.

Krebs, J.R., Dawkins, R., 1978. Animal signals: mind-Reading and manipulation. In: Krebs, J.R., Dawkins, R. (Eds.), Behavioural Ecology. An Evolutionary Approach. Blackwell Scientific Publications, Oxford, p. 381.

Levenson, R.W., Ekman, P., Friesen, W.V., 1990. Voluntary facial action generates emotion-Specific autonomic nervous system activity. Psychophysiology 27, 363-384.

Liebal, K., Waller, B., Burrows, A.M., Slocombe, K.E., 2013. Primate Communication. A Multimodal Approach. Cambridge University Press, New York.

Mancini, G., Ferrari, P.F., Palagi, E., 2013a. Rapid facial mimicry in geladas. Sci. Rep. 3, 1527, http://dx.doi.org/10.1038/srep01527.

Mancini, G., Ferrari, P.F., Palagi, E., 2013b. In play we trust. Rapid facial mimicry predicts the duration of playful interactions in geladas. PLoS One 8, e66481, http://dx.doi.org/10.1371/journal.pone.0066481.

Micheletta, J., Engelhardt, A., Matthews, L., Agil, M., Waller, B.M., 2013. Multicomponent and multimodal lipsmacking in crested macaques (Macaca nigra). Am. J. Primatol. 75, 763-773, http://dx.doi.org/10.1002/ajp.22105.

Micheletta, J., Whitehouse, J., Parr, L.A., Waller, B.M., 2015. Facial expression recognition in crested macaques (Macaca nigra). Anim. Cogn., http://dx.doi. org/10.1007/s10071-015-0867-z.

Miller, R.E., 1971. Experimental studies of communication in the monkey. In: Rosenblum, L.A. (Ed.), Primate Behaviour: Developments in Field and Laboratory Research. Academic Press, New York and London.

Morimoto, Y., Fujita, K., 2011. Capuchin monkeys (Cebus apella) modify their own behaviors according to a conspecific's emotional expressions. Primates 52, 279-286, http://dx.doi.org/10.1007/s10329-0110249-3. 
Morimoto, Y., Fujita, K., 2012. Capuchin monkeys (Cebus apella) use conspecifics' emotional expressions to evaluate emotional valence of objects. Anim. Cogn. 15, 341-347, http://dx.doi.org/10.1007/s10071-011-0458-6.

Morris, J.S., Frith, C.D., Perrett, D.I., Rowland, D., Young, A.W., Calder, A.J., Dolan, R.J., 1996. A differential neural response in the human amygdala to fearful and happy facial expressions. Nature $383,812-$ 815.

Panksepp, J., 1990. The psychoneurology of fear: evolutionary perspectives, the role of animal models in understanding human anxiety. In: Burrows, G.D., Roth, M., Noyer, R. (Eds.), Handbook of Anxiety. Volume. The Neurobiology of Anxiety. Elsevier Science BV, Amsterdam, The Netherlands, pp. 3-58.

Parr, L.A., Hecht, E.E., 2011. Facial perception in non-human primates. In: Calder, A.J., Rhodes, G., Johnson, M.H., Haxby, J.V. (Eds.), The Oxford Handbook of Face Perception. Oxford University Press, New York, pp. 691-706.

Parr, L.A., Heintz, M., 2009. Facial expression recognition in rhesus monkeys, Macaca mulatta. Anim. Behav. 77, 1507-1513, http://dx.doi.org/10.1016/j. anbehav.2009.02.024.Facial.

Parr, L.A., Hopkins, W.D., De Waal, F.B.M., 1998. The perception of facial expressions by chimpanzees, pan troglodytes. Evol. Commun. 2, 1-23, http:// dx.doi.org/10.1075/eoc.2.1.02par.

Parr, L.A., Waller, B.M., Heintz, M., 2008. Facial expression categorization by chimpanzees using standardized stimuli. Emotion 8, 216-231, http://dx.doi. org/10.1037/1528-3542.8.2.216.

Parr, L.A., Waller, B.M., Vick, S.J., Bard, K.A., 2010. Classifying chimpanzee facial expressions using muscle action. Emotion 7, 172-181, http://dx.doi.org/10. 1037/1528-3542.7.1.172.

Parr, L.A., Waller, B.M., Gothard, K.M., Vick, S.J., 2011. MaqFACS: a muscle-based facial movement coding system for the rhesus macaque. Am. J. Phys. Anthropol. 143, 625-630, http://dx.doi.org/10.1002/ajpa.21401.MaqFACS.

Parr, L.A., 2001. Cognitive and physiological markers of emotional awareness in chimpanzees (Pan troglodytes). Anim. Cogn. 4, 223-229, http://dx.doi.org/10. 1007/s100710100085.

Partan, S., Marler, P., 1999. Communication goes multimodal. Science 238 (80), 1272-1273.

Phillips, M.L., Drevets, W.C., Rauch, S.L., Lane, R., 2003. Neurobiology of emotion perception I: the neural basis of normal emotion perception. Biol. Psychiatry 54, 504-514, http://dx.doi.org/10.1016/S00063223(03)00168-9.

Pika, S., 2008. Evidence for intentional and referential communication in great apes? In: Zlatev, J., Racine, T., Sinha, C., Itkonen, E. (Eds.), The Shared Mind: Perspectives on Intersubjectivitiy. Benjamins, Amsterdam, pp. 165-186.

Preuschoft, S., van Schaik, C.P., 2000. Dominance and communication. In: Natural Conflict Resolution. University of California Press, London, UK.

Rosati, A.G., Hare, B., 2012. Decision making across social contexts: competition increases preferences for risk in chimpanzees and bonobos. Anim. Behav. 84, 869-879, http://dx.doi.org/10.1016/j.anbehav.2012.07.010.

Schel, A.M., Townsend, S.W., Machanda, Z., Zuberbühler, K., Slocombe, K.E., 2013. Chimpanzee alarm call production meets key criteria for intentionality. PLoS One 8, e76674, http://dx.doi.org/10.1371/journal.pone.0076674.

Schmidt, K.L., Cohn, J.F., 2001. Human facial expressions as adaptations: evolutionary questions in facial expression research. Am. J. Phys. Anthropol. Suppl. 33, 3-24, http://dx.doi.org/10.1002/ajpa.20001. 
Seyfarth, R.M., Cheney, D.L., Marler, P., 1980. Vervet monkey alarm calls: semantic communication in a free-ranging primate. Science 210 (80), 801-803, http:// dx.doi.org/10.1016/S0003-3472(80)800972.

Shariff, A.F., Tracy, J.L., 2011. What are emotion expressions for? Curr. Dir. Psychol. Sci. 20, 395-399, http://dx.doi.org/10.1177/0963721411424739.

Slocombe, K.E., Kaller, T., Turman, L., Townsend, S.W., Papworth, S., Squibbs, P., Zuberbühler, K., 2010. Production of food-associated calls in wild male chimpanzees is dependent on the composition of the audience. Behav. Ecol. Sociobiol. 64, 1959-1966, http://dx.doi.org/10.1007/s00265-010-10060 .

Steiner, J.E., Glaser, D., Hawilo, M.E., Berridge, K.C., 2001. Comparative expression of hedonic impact: affective reactions to taste by human infants and other primates. Neurosci. Biobehav. Rev. 25, 5374.

Susskind, J.M., Lee, D.H., Cusi, A., Reiman, R., Grabski, W., Anderson, A.K., 2008. Expressing fear enhances sensory acquisition. Nat. Neurosci., 843-850, http:// dx.doi.org/10.1038/nn.2138.

Thierry, B., Demaria, C., Preuschoft, S., 1989. Structural convergence between silent bared-teeth display and relaxed open-mouth display in the Tonkean macaque (Macaca tonkeana). Foila Friomatol. 52, 178-184.

Thierry, B., Bynum, E.L., Baker, S., Kinnaird, M.F., Matsumura, S., Muroyama, Y., O’Brien, T.G., Petit, O., Watanabe, K., 2000. The social repertoire of sulawesi macaques. Primate Res. 16, 203-226, http://dx.doi.org/10.2354/psj.16.203.

Tinbergen, N., 1963. On aims and methods of ethology. Z. Tierpsychol., 410-433.

Tomasello, M., Call, J., Hare, B., 1998. Five primate species follow the visual gaze of conspecifics. Anim. Behav. 55, 1063-1069, http://dx.doi.org/10.1006/anbe.1997.0636.

Tomasello, M., 2008. Origins of Human Communication. MIT Press, London, UK. Van Hoof, J.A., Hinde, R.A., 1972. A Comparative Approach to the Phylogeny of Laughter and Smiling. In: Mehrabian, A. (Ed.). Cambridge University Press, Oxford, England, p. 443.

Vick, S., Waller, B.M., Parr, L.A., Bard, K.A., 2007. A cross-species comparison of facial morphology and movement in humans and chimpanzees using the facial action coding system (FACS). J. Nonverbal Behav. 31, 1-20, http://dx.doi.org/ 10.1007/s10919-006-0017-z.

Waller, B.M., Bard, K.A., Vick, S.J., Smith Pasqualini, M.C., 2007. Perceived differences between chimpanzee (Pan troglodytes) and human (Homo sapiens) facial expressions are related to emotional interpretation. J. Comp. Psychol. 121, 398-404.

Waller, B.M., Lembeck, M., Kuchenbuch, P., Burrows, A.M., Liebal, K., 2012.

GibbonFACS: A Muscle-Based Facial Movement Coding System for Hylobatids. Int. J. Primatol. 33, 809-821, http://dx.doi.org/10.1007/s10764-012-9611-6.

Waller, B.M., Misch, A., Whitehouse, J., Herrmann, E., 2014. Children, but not chimpanzees, have facial correlates of determination. Biol. Lett. 10, 20130974, http://dx.doi.org/10.1098/rsbl.2013.0974.

Waller, B.M., Caeiro, C.C., Davila-Ross, M., 2015. Orangutans modify facial displays depending on recipient attention. PeerJ 3, e827, http://dx.doi.org/10.7717/ peerj.827.

Waller, B.M., Whitehouse, J., Micheletta, J., 2016. Macaques can predict social outcomes from facial expressions. Anim. Cogn., http://dx.doi.org/10.1007/ s10071-016-0992-3.

Watson, S.K., Townsend, S.W., Schel, A.M., Wilke, C., Wallace, E.K., Cheng, L., West, V., Slocombe, K.E., 
2015. Vocal learning in the functionally referential food grunts of chimpanzees. Curr. Biol. 25 (4), 495-499, http://dx.doi.org/10.1016/j. cub.2014.12.032.

Whalen, P.J., Kagan, J., Cook, R.G., Davis, F.C., Kim, H., Polis, S., Mclaren, D.G., Somerville, L.H., Mclean, A.A., Maxwell, J.S., Johnstone, T., 2004. Human amygdala responsivity to masked fearful eye whites. Science 306 (80), 2061.

Wheeler, B.C., Fischer, J., 2012. Functionally referential signals: a promising paradigm whose time has passed. Evol. Anthropol. Issues News Rev. 21, 195-205, http://dx.doi.org/10.1002/evan.21319.

Whiten, A., 2013. Humans are not alone in computing how others see the world. Anim. Behav. 86, 213221, http://dx.doi.org/10.1016/j.anbehav.2013.04.021.

Wilson, T.D., Gilbert, D.T., 2005. Affective forecasting. Knowing what to want. Curr. Dir. Psychol. Sci. 14, 131-134. 